\title{
Analysis of the EHEC hly operon and its location in the physical map of the large plasmid of enterohaemorrhagic Escherichia coli 0157:H7
}

\author{
Herbert Schmidt, Christian Kernbach and Helge Karch
}

\begin{abstract}
Author for correspondence: Herbert Schmidt. Tel: +49 931 2015160. Fax: +49 9312013445 e-mail: hschmidt@hygiene.uni-wuerzburg.d400.de
\end{abstract}

Institut für Hygiene und Mikrobiologie der Universităt Würzburg, Josef-Schneider-Straße 2 , 97080 Würzburg,

Germany

\begin{abstract}
Almost all clinical enterohaemorrhagic Escherichia coli (EHEC) 0157:H7 isolates harbour a large virulence plasmid designated p0157. In this study, p0157 of EHEC 0157:H7 reference strain EDL 933 was characterized at the molecular level. A restriction map was constructed by using seven restriction enzymes, with appropriate gel electrophoretic and hybridization methods. The molecular size of p0157 was determined to be $93.6 \mathrm{~kb}$. By sequencing the DNA region extending in the 3'-direction of the previously described EHEC hlyC and hlyA genes, two further genes were discovered and analysed; these were termed EHEC hlyB and EHEC hlyD. The newly discovered genes together with the EHEC $h / y C$ and hlyA genes constitute a typical RTX (Repeats in ToXin) determinant (EHEC hly operon) with the gene order CABD. The map position of the operon was determined by hybridization experiments. Analysis of a DNA fragment carrying the downstream flanking region of the EHEC hly operon revealed an open reading frame which was highly homologous to orf1 of RepFIB, a basic replicon of IncF plasmids. It was located close to the EHEC hly operon.
\end{abstract}

Keywords: enterohaemorrhagic Escherichia coli O157:H7, plasmid pO157, EHEC bly operon, blyBD genes, RTX determinant

\section{INTRODUCTION}

Enterohaemorrhagic Escherichia coli (EHEC) O157:H7 is a major cause of serious outbreaks as well as sporadic cases of haemorrhagic colitis (HC) and classical haemolytic uraemic syndrome (HUS) (Tarr, 1995; Griffin \& Tauxe, 1991). Since it was first described in 1983 (Riley $e t$ al., 1983; Wells et al., 1983), this organism has emerged as an important public health concern world-wide (O'Brien et al., 1992; Griffin \& Tauxe, 1991). Shiga-like toxins are considered to be the major pathogenic factors of E. coli O157:H7 (Tesh \& O’Brien, 1991; Tarr, 1995). The production of intimin ${ }_{\mathrm{O} 157}$ is an important virulence characteristic of this bacterium. Intimin ${ }_{0157}$ is a $97 \mathrm{kDa}$ outer-membrane protein involved in the intimate bacterial

Abbreviations: HC, haemorrhagic colitis; HUS, haemolytic uraemic syndrome; EHEC, enterohaemorrhagic Escherichia coli; RTX, Repeats in ToXin; CFGE, constant-field-gel electrophoresis.

The GenBank accession numbers for the nucleotide sequences of the EHEC hly operon and the EHEC orf1 are X86087 and X85737, respectively. attachment-effacement of the gut epithelium and actin aggregation in cells to which E. coli O157:H7 adheres (Yu \& Kaper, 1992; Dytoc et al., 1993; Louie et al., 1993; Tzipori et al., 1995). Auxiliary virulence mechanisms like the production of fimbrial antigens (Karch et al., 1987) and exopolysaccharide (Fratamico et al., 1993), and tolerance of acidic environments (Benjamin \& Datta, 1995), are only partially understood.

A large plasmid of approximately $90 \mathrm{~kb}$ (pO157) is present in virtually all clinical $\mathrm{O} 157$ isolates and several studies have been carried out to clarify the plasmid's function. Most of these studies have addressed the adherence properties of EHEC O157:H7 strains to cultured eukaryotic cells. Whereas some of the authors described a plasmid-dependent adherence to HEp-2 and Int 407 cells, others could not confirm these observations (Karch $e$ t al., 1987; Toth et al., 1990; Fratamico et al., 1993; Sherman et al., 1987; Junkins \& Doyle, 1989). Wadolkowski et al. (1990) reported that the plasmid-cured EDL933-cu could not compete with strain EDL933 for colonization of the streptomycin-treated mouse bowel. They suggested that the $90 \mathrm{~kb}$ plasmid might encode a required factor for $E$. 
coli $\mathrm{O} 157: \mathrm{H} 7$ strains to colonize in the presence of other bacteria. In contrast, by using the gnotobiotic piglet model, plasmid pO157 could not be shown to promote proliferation or colonization of EHEC O157: $\mathrm{H} 7$ strain EDL933 in the gastrointestinal tract (Tzipori et al., 1986, 1987). Further studies on pO157 included the invasion characteristics of EHEC O157 in cultured bladder and colonic cells (Oelschlaeger et al., 1994), the influence on attaching and effacing adhesion (Toth et al., 1990), the regulation of the chromosomal eae $A$ gene (Gomez-Duarte $\&$ Kaper, 1995) and the expression of plasmid-encoded proteins (Fratamico et al., 1993). However, none of the studies provided definite proof of the importance of pO157 in the expression of EHEC virulence. As only single aspects of EHEC infections may be studied using the animal models currently available, efforts to elucidate the direct influence of plasmid pO157 on multisymptomatic HUS have been impeded.

Recently, we described a novel pO157-encoded protein of EHEC O157: H7 which was designated EHEC haemolysin (Schmidt et al., 1995). This protein belongs to the RTX (Repeats in ToXin) family of pore-forming cytolysins and shares high sequence similarity with $E$. coli $\alpha-$ haemolysin (Schmidt et al., 1995). RTX toxins represent a family of important virulence factors that are widely distributed among $\mathrm{Gram}$-negative bacteria and are defined by a glycine-rich signature nonamer repeated several times in the C-terminal region of the protein (Coote, 1992; Welch, 1991, 1995). RTX proteins share some common features and may function as proteases, lipases, or pore-forming cytolysins, the latter of which kill a variety of target cells by building pores due to their integration in target cell membranes (Coote, 1992; Welch, 1995).

The enterohaemolytic phenotype of EHEC O157: $\mathrm{H} 7$ is caused by EHEC haemolysin (Schmidt et al., 1995). This specific mode of haemolytic activity can be recognized by the appearance of small, turbid zones of haemolysis on blood agar plates with washed erythrocytes after 18-24 h incubation at $37^{\circ} \mathrm{C}$. In contrast, $\alpha$-haemolysin causes big, clear zones of haemolysis after $4-6 \mathrm{~h}$ incubation at $37^{\circ} \mathrm{C}$ on standard blood agar plates. When strains are grown in liquid culture, EHEC haemolysin remains cell-associated (Schmidt et al., 1995), whereas $\alpha$-haemolysin is exported into the culture supernatant via a specific membrane translocator system consisting of $\mathrm{HlyB}, \mathrm{HlyD}$ and the outer-membrane protein TolC (Fath \& Kolter, 1993; Welch, 1991; Wandersman \& Delepelaire, 1990). Furthermore, EHEC haemolysin triggers a specific immune response in patients suffering from O157: $\mathrm{H} 7$-associated HUS (Schmidt et al., 1995), indicating that it is produced during the infectious stage.

The purpose of this study was to provide a basic molecular foundation to further investigate plasmid pO157 and the EHEC haemolysin operon with respect to the biological functions and pathogenic properties of EHEC O157:H7. Data from restriction mapping and nucleotide sequence analyses should enable coordinated genetic studies including investigation of the regulation of gene expression, biological activity of plasmid-encoded proteins and the role of pO157 during E. coli $\mathrm{O} 157: \mathrm{H} 7$ infections.

\section{METHODS}

Bacterial strains, plasmids and culture conditions. The EHEC O157:H7 strain EDL933 was isolated from a patient with haemorrhagic colitis; it harbours the large virulence plasmid pO157 $(\sim 90 \mathrm{~kb})$ and one smaller plasmid of $3.3 \mathrm{~kb}$ (Karch $e t$

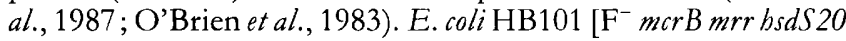
$\left(\mathrm{r}_{\mathrm{B}}^{-} \mathrm{m}_{\mathrm{B}}^{-}\right) \operatorname{rec} A 13$ leuB6 ara-14 proA2 lac Y1 galK2 xyl-5 mtl-1 rpsL20 supE44 $\lambda^{-}$] was used as host for recombinant plasmids. Plasmid pSK 3 is a derivative of pO157 obtained by transposon mutagenesis with the temperature-sensitive $\operatorname{Tn} 801$, which is a member of the Tn3 family (Karch et al., 1987; Heffron, 1983; Schmidt et al., 1994). For large-scale multiplication of plasmid DNA this strain was grown for at least $18 \mathrm{~h}$ in L-broth (for pSK 3 at $30^{\circ} \mathrm{C}$, for all other plasmids at $37^{\circ} \mathrm{C}$ ) with vigorous shaking. Plasmid pK18 was used as cloning vector (Pridmore, 1987).

General recombinant DNA techniques. Large-scale purifications of pSK3 and pO157 were performed with the Qiagen plasmid kit according to the manufacturer's instructions for low-copy-number plasmids; $\mathrm{pK} 18$ derivatives were prepared by the regular protocol (Qiagen Plasmid Handbook). For maintenance of recombinant plasmids $100 \mu \mathrm{g}$ ampicillin $\mathrm{ml}^{-1}$ (pSK3) or $50 \mu \mathrm{g}$ kanamycin $\mathrm{ml}^{-1}$ (pK18 derivatives) was added to the culture media. For restriction endonuclease cleavage of $\mathrm{pSK} 3$, pO157 and subclones the six-cutters AccI, BamHI, ClaI, EcoRI, HindIII, PstI and SalI, and the rare-cutting enzymes RsrII, SfiI, SpeI and $\mathrm{XbaI}$ (all from New England Biolabs) were selected in order to create suitable amounts and sizes of restriction fragments. Restriction endonuclease digestions were carried out according to the supplier's instructions. DNA fragments were purified from agarose gels using the Prep-a-Gene kit (Bio-Rad). Ligation and transformation experiments were carried out by standard methods (Sambrook et al., 1989).

Agarose gel electrophoresis and restriction fragment size determination. The size of pSK3 and pO157 (>90 kb) necessitates the separation of restriction enzyme digests by constant-field (CFGE) and pulsed-field gel electrophoresis (PFGE). For CFGE, $0 \cdot 6-2 \%(\mathrm{w} / \mathrm{v})$ submarine agarose gels $(12 \mathrm{~cm} \times 18 \mathrm{~cm})$ were used. In order to create sharp and wellseparated bands, a maximum electrical gradient of $5 \mathrm{~V} \mathrm{~cm}^{-1}$ was applied. The concentration of DNA loaded on the gel was adjusted to approximately $10-20 \mathrm{ng}$ per visible band. Under these conditions fragments ranging from 0.1 to $7 \mathrm{~kb}$ were properly separated in the logarithmic zone of the gel. Nonseparable large bands located in the compressed zone of the constant-field gels could be separated by PFGE in a horizontal, CHEF-configured pulsed-field apparatus (Bio-Rad) with 0.5 fold concentrated Tris/borate/EDTA (TBE) buffer at $12{ }^{\circ} \mathrm{C}$. The voltage was maintained at $170 \mathrm{~V}$ with a constant pulse time of $3 \mathrm{~s}$. The restriction enzyme digests, containing $30-50 \mathrm{ng}$ DNA, were loaded directly into the slots of a $1 \%(\mathrm{w} / \mathrm{v})$ highpurity agarose gel (agarose III, PFGE grade, Amresco) and electrophoresed for $16 \mathrm{~h}$. Large restriction fragments ranging from 5 to $100 \mathrm{~kb}$ could be separated under these conditions.

By comparing restriction enzyme digestions separated on different gels, it was possible to estimate fragment sizes between 0.1 and $98 \mathrm{~kb}$ with an error of less than $0.5 \%$. Measurement of bands was performed on enlarged prints of the gels. Restriction fragment sizes were determined by comparing the migrations of the fragments with a calibration graph constructed with the 
migrations of size markers separated on the same gel. Size markers were the High Molecular Weight DNA Marker (GibcoBRL) the Low-range PFG Marker (New England Biolabs) and the $1 \mathrm{~kb}$ DNA Ladder (GibcoBRL).

Southern blot hybridization. DNA was transferred from agarose gels to Zeta-probe nylon-membranes (Bio-Rad) by standard methods (Sambrook et al., 1989). For hybridization assays, the Boehringer Non-radioactive DNA Labelling and Detection Kit was used, according to the manufacturer's instructions. Hybridization was performed by incubating the membrane in hybridization solution for $18 \mathrm{~h}$ in a $60^{\circ} \mathrm{C}$ water bath. The specific washing step was carried out twice at $60^{\circ} \mathrm{C}$ for $5 \mathrm{~min}$ in $0.03 \times \mathrm{SSC}(4.5 \mathrm{mM}$ sodium chloride, $0.45 \mathrm{mM}$ sodium citrate) and $0.1 \%(\mathrm{w} / \mathrm{v})$ SDS to effect a stringency of $95 \%$. Probes were labelled with digoxigenin-11-dUTP either randomly or by PCR as described previously (Schmidt et al., 1993).

PCR. PCR for creation of gene probes specific for $\operatorname{Tn} 801$ was performed in the GeneAmp PCR System 9600 (Perkin ElmerApplied Biosystems). Amplification was carried out in a total volume of $50 \mu \mathrm{l}$ containing each deoxynucleosidetriphosphate at $200 \mu \mathrm{M}, 30 \mathrm{pmol}$ of each primer [801-start (5'-CGG CAG TGA GAG CAG AGA TAG-3') and 801-stop (5'-GAG GTA GTC ACA GGC ATT CAG-3')], $5 \mu$ l tenfold-concentrated polymerase synthesis buffer containing $1.5 \mathrm{mM} \mathrm{MgCl}_{2}$ and 2.0 U AmpliTaq DNA polymerase (Perkin Elmer-Applied Biosystems). The DNA was denatured at $94^{\circ} \mathrm{C}$ for $45 \mathrm{~s}$, annealed at $53{ }^{\circ} \mathrm{C}$ for $60 \mathrm{~s}$, and then extended for $120 \mathrm{~s}$ at $72^{\circ} \mathrm{C}$. After 30 cycles were completed, a final extension step of $5 \mathrm{~min}$ at $72{ }^{\circ} \mathrm{C}$ was conducted. PCR for preparing gene probes specific for EHEC bly $A$ was carried out as described previously (Schmidt et al., 1995).

DNA sequencing. This was carried out with universal and reverse primers for pUC/M13 vectors and customized primers as described previously (Schmidt et al., 1995). Nucleotide sequence analyses and the searches for homologous DNA sequences in the EMBL and GenBank database libraries were performed with the program package HUSAR (Heidelberg UNIX Sequence Analysis Resources, German Cancer Research Centre, Heidelberg) and the DNAsis program package (Hitachi).

\section{RESULTS}

\section{Construction of the physical map of recombinant plasmid pSK3}

Due to the presence of two plasmids in strain EDL 933 and the large amounts of plasmid DNA necessary to adjust gel-electrophoretic conditions, Tn801-tagged plasmid pSK3 (Schmidt et al., 1994) was chosen for primary restriction analysis. This plasmid can be easily transferred and propagated in the non-pathogenic E. coli laboratory strain HB101.

First, a provisional restriction map was constructed using the rare-cutting enzymes Sfil, SpeI and XbaI. This was accomplished by comparing the restriction fragment sizes resulting from single and double digests. Cleavage with $B a m \mathrm{HI}, C l a \mathrm{I}, E c o \mathrm{RI}$ and RsrII generated numerous fragments which could not be mapped by this conventional method. To address this, supplementary techniques were used. We hybridized restriction enzyme digests of pSK3 with an EHEC bly $A$-specific probe and found an approximately $12 \mathrm{~kb}$ EcoRI fragment suitable

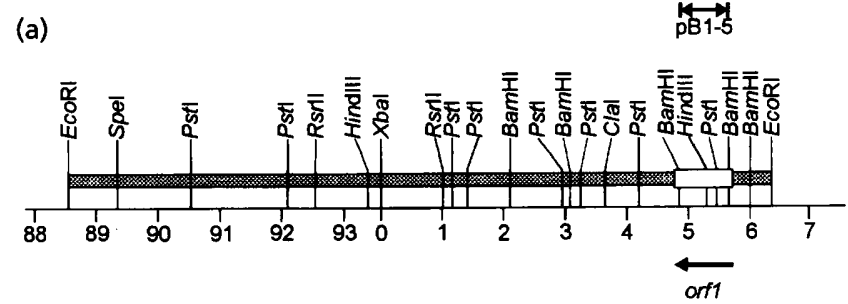

(b)
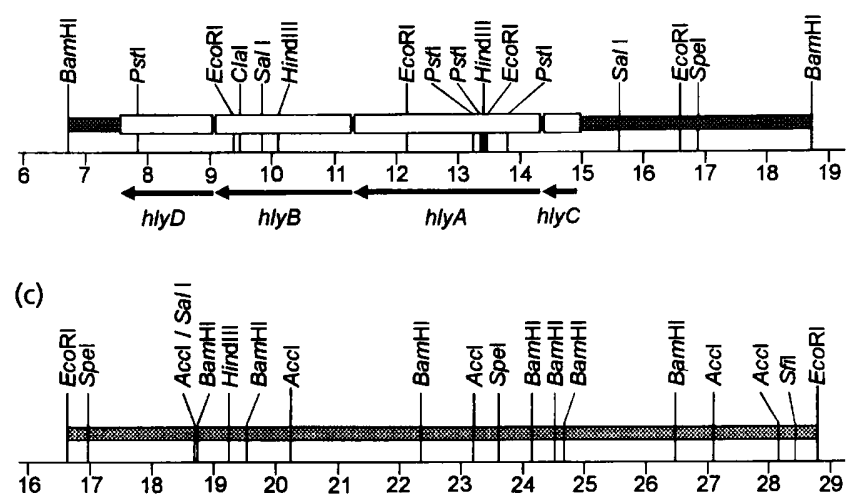

Fig. 1. Detailed linear restriction enzyme maps of subclones derived from pSK3. In (a) and (c), the $11.4 \mathrm{~kb}$ (pE11) and $12.1 \mathrm{~kb}$ (pE12) EcoRI fragments are shown. The complete restriction map of the $12.0 \mathrm{~kb}$ (pB12) fragment carrying the EHEC h/y determinants is shown in (b). ORFs are depicted by boxes. Arrows indicate the direction of transcription. The distances in $\mathrm{kb}$ indicated below the maps are in accordance with Fig. 2 .

for subcloning in pK18. Analysis of transformants revealed that two EcoRI fragments of similar sizes had been cloned. To map these EcoRI fragments of $11.4 \mathrm{~kb}$ (pE11, Fig. 1a) and $12 \cdot 1 \mathrm{~kb}$ (pE12, Fig. 1c) with the above-mentioned enzymes, it was necessary to use the additional enzymes AccI, HindIII, Pst I and SalI. To correctly assign the $12 \mathrm{~kb}$ Bam HI fragment (pB12 = pEO40) containing the EHEC haemolysin operon (Schmidt et al., 1995) to the pSK3 map, the restriction map of $\mathrm{pEO} 40$ was supplemented with restriction sites for the enzymes ClaI and SpeI (Fig. 1b).

The three subclones were randomly labelled with digoxigenin and hybridized with several restriction enzyme digests of pSK3. The results of these hybridizations allowed us to determine the locations of the subclones in the SfiI-SpeI-XbaI map. In doing this, a large proportion of the restriction fragments created with the other enzymes could be arranged in a provisional restriction map. To determine the position of the remaining fragments in the map we performed cross-hybridizations: suitable restriction fragments were excised from agarose gels, randomly labelled with digoxigenin, and hybridized with restriction enzyme digests of $\mathrm{pSK} 3$ using all seven enzymes. By comparing the resulting hybridization signals we were able to detect related fragments, coordinate all restriction sites, and construct the physical map of the entire plasmid pSK3. One of the two XbaI sites was designated as the starting point of the map. The size 


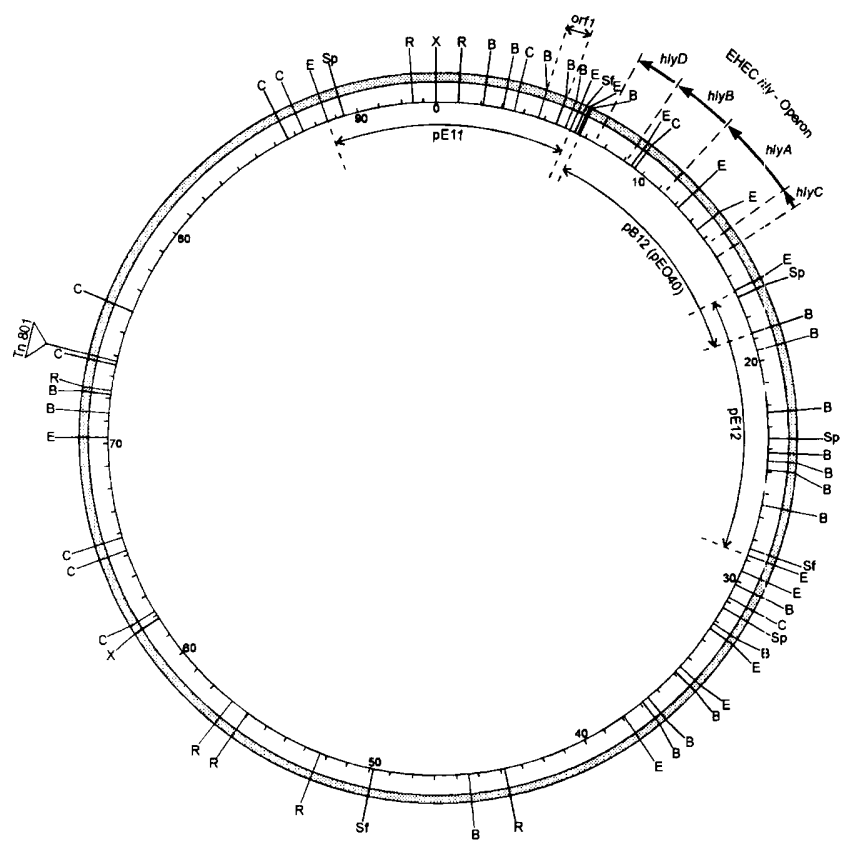

Fig. 2. Circular restriction map of wild-type plasmid p0157. The restriction sites for $X$ bal (X), Spel (S), Sfil (Sf), EcoRI (E), BamHI (B), Clal (C), and Rsrll (R) are indicated. These sites are positioned with respect to the $X b a l$ site at coordinate $D$, and the map is numbered by distance (in kb) from that site. The site of insertion of $\mathrm{Tn} 801$ is indicated at position 73.8 of the map. The positions of subclones pE11, pB12 (pEO40) and pE12 are indicated by curved arrows. At position 7.8-15, the EHEC hly operon with genes $h / y C, h / y A, h l y B$ and $h / y D$ is depicted by bold arrows. EHEC orf1 spans the region from $4.7 \mathrm{~kb}$ to $5.6 \mathrm{~kb}$.

of pSK3 (containing Tn801) was estimated to be $98 \cdot 6 \mathrm{~kb}$ by summation of all fragment sizes from each digest.

\section{Location of Tn801 and reconstruction of the physical map of p0157}

To reconstruct the map of the wild-type plasmid pO157, it was necessary to determine the position of Tn 801 in pSK3. Restriction of Tn 801 with Pst I should yield a $2.8 \mathrm{~kb}$ and a $0.7 \mathrm{~kb}$ Pst I fragment (Grinstedt $e t$ al., 1977; Heffron, 1983). We cloned the corresponding $2.8 \mathrm{~kb}$ Pst $\mathrm{I}$ fragment derived from $\mathrm{pSK} 3$ in the vector $\mathrm{pK} 18$ to achieve a transposon-specific probe. The resulting clone was resistant to ampicillin, suggesting that it harboured the $\beta$-lactamase gene of $\operatorname{Tn} 801$. Following partial sequence analysis of the $2.8 \mathrm{~kb}$ insert, a search of the EMBL database library revealed $>92 \%$ sequence similarity to transposase-encoding genes typically found in transposons of the Tn 3 family (Heffron et al., 1979). The DNA sequences were used to design PCR primers for PCRmediated probe-labelling. The resulting $2.5 \mathrm{~kb}$ Tn 801 probe was hybridized with selected restriction enzyme digests of pSK3 and pO157. By analysing the hybridization results and comparing the restriction patterns of pSK3, pO157 and Tn801, we were able to determine the location of Tn801 as well as deduce the restriction map of the parental wild-type plasmid pO157
Table 1. Sizes (kb) of BamHI, Clal, EcoRI, Rsrll, Sfil, Spel and $X$ bal restriction fragments of wild-type plasmid p0157

\begin{tabular}{|c|c|c|c|c|c|c|}
\hline BamHI & ClaI & EcoRI & $R s r I I$ & SfiI & SpeI & $X b a I$ \\
\hline $25 \cdot 9$ & $31 \cdot 4$ & $32 \cdot 4$ & $42 \cdot 8$ & $50 \cdot 3$ & $58 \cdot 0$ & $61 \cdot 8$ \\
\hline $23 \cdot 5$ & $21 \cdot 3$ & $18 \cdot 3$ & $20 \cdot 1$ & $21 \cdot 9$ & $21 \cdot 2$ & $31 \cdot 8$ \\
\hline $12 \cdot 0$ & $10 \cdot 6$ & $12 \cdot 1$ & $15 \cdot 5$ & $21 \cdot 4$ & $7 \cdot 7$ & \\
\hline $8 \cdot 6$ & $9 \cdot 8$ & $11 \cdot 4$ & $8 \cdot 5$ & & $6 \cdot 6$ & \\
\hline $3 \cdot 7$ & $7 \cdot 8$ & $3 \cdot 3$ & $3 \cdot 7$ & & & \\
\hline $2 \cdot 8$ & $5 \cdot 9$ & $3 \cdot 2$ & $2 \cdot 0$ & & & \\
\hline $2 \cdot 7$ & $3 \cdot 0$ & $2 \cdot 8$ & 0.9 & & & \\
\hline $2 \cdot 0$ & $2 \cdot 4$ & $2 \cdot 8$ & & & & \\
\hline $1 \cdot 8$ & 0.74 & $2 \cdot 7$ & & & & \\
\hline $1 \cdot 8$ & 0.6 & $2 \cdot 2$ & & & & \\
\hline $1 \cdot 7$ & & $0 \cdot 8$ & & & & \\
\hline $1 \cdot 7$ & & $0 \cdot 3$ & & & & \\
\hline $0 \cdot 95$ & & & & & & \\
\hline $0 \cdot 8$ & & & & & & \\
\hline $0 \cdot 8$ & & & & & & \\
\hline 0.7 & & & & & & \\
\hline 0.7 & & & & & & \\
\hline $0 \cdot 4$ & & & & & & \\
\hline $0 \cdot 35$ & & & & & & \\
\hline $0 \cdot 25$ & & & & & & \\
\hline $0 \cdot 15$ & & & & & & \\
\hline
\end{tabular}

(Fig. 2). The fragment sizes resulting from digestion of pO157 with the seven enzymes mentioned above are shown in Table 1. The size of pO157 from strain EDL933 was estimated to be $93.6 \mathrm{~kb}$.

\section{DNA sequence analysis of the EHEC $h / y B$ and $h l y D$ genes and location of the EHEC hly operon in the p0157 map}

The two genes EHEC bly $C$ and EHEC bly $A$ were recently described to be located on a $12 \mathrm{~kb} \mathrm{BamHI}$ (pEO40) fragment of pO157 (Schmidt et al., 1995). Following analysis of that portion of pEO40 extending in the $3^{\prime}$ direction of the bly $A$ gene, we discovered another two open reading frames (ORFs), of $2121 \mathrm{bp}$ and $1440 \mathrm{bp}$, capable of encoding proteins of 706 and 479 amino acids, respectively. Searching the EMBL database revealed high similarities of $69 \%$ and $62 \%$ to the genes bly $B$ and $b l y D$ of the $\alpha$-haemolysin operon; the genes were consequently termed EHEC hlyB and EHEC blyD. Since two tandemly arranged ATG codons preceded the EHEC blyB gene, the translational start point could not be clearly deduced from the sequence. A spacing region of $49 \mathrm{bp}$ with the ability to build a stem-loop structure is located between the termination codon of the EHEC bly $A$ gene and the putative start codon of the EHEC blyB gene. The EHEC $b l y B$ and $b l y D$ genes are separated by only three nucleotides. The putative proteins share high identity with other RTX proteins. Highest similarities were found with HlyB $(72.9 \%)$ and HlyD $(56.8 \%)$, encoded by the E. coli $\alpha$ haemolysin operon, as well as with LktB $(71.3 \%)$ and 
(a)

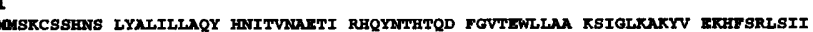
-D-CHRIDYG -Y--EI- - --VSV-P-8- X-RTDTDGTG LGL-S----- --LE--VRQV R-TID--NFI

71 SLPALIWRDD GKHYILSRIT KDSSRYLVYD PEQHQSLTYS RDEFERLYQG KVILVTSRAT VVGELAKFDF

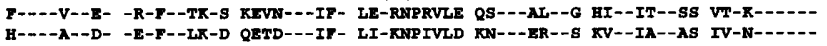
141 SWFIPSVVKY RRILLEVLTV SATIQFLALI TPLFFQVVAD KVLVRRGFST LNIITIAYII VILFEVILTC T---AII-- -R-F--T-V- -V-L-LF--- -...--- - T---AVI-- -R-F--T-I- -I-L-IF-- - -

ARTYITSHTY SRIDVELGAK LFRELLALPV SYFENRRVGE TVARVREEDQ IRNFLTCQAI TSVLDLFFSV

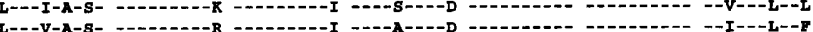

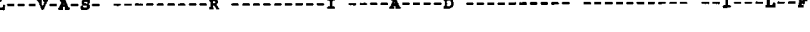

281

IFFCVMGYYS PQLTLVI-LS LPCYVIWSLF ISPLLRRRUD DKFLRNAENQ AFLVETVTAI NTIKSWAVSP

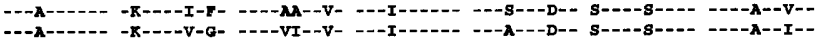

351

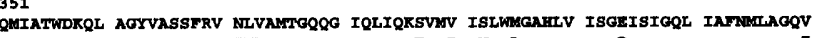

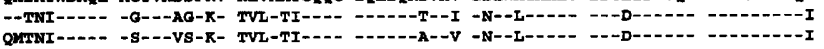
421

IAPVIRLAHC WQDFQQVGIS VERLGDVLNY PVEKRSGRNI LPEIQGDIEF RNVRFRYSSD ONVILNANINL VA-The 491 YISXGDVIGI VORSOBGKSP LTKLLQRYYI PETGQILIDG HDLSLADPEW LRRQIGVVLQ ENILLARSII YISKGDVIGI VORSGSGKST LTKLLQRTYI PETGQILIDG HDLSLADPEW LRRQIGVVLO ENILLARSII
S-KQ-E-
D-SO-E--

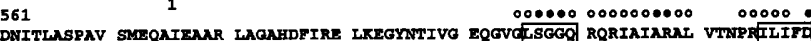
D--S-AN-GM SV-KV-Y-K 2

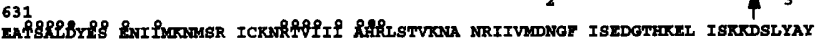

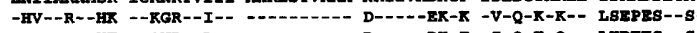

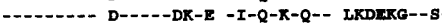
4

LYQLQA....

Y-.-SD...

(b)

1 MRTMTKOLWD LVCRYKTVYS DVWRIRHTLD APVREKDEYA FLPAHLIILIE TPVSRRGECV VWSILLFVII

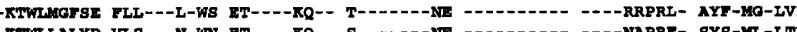

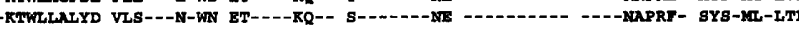

71

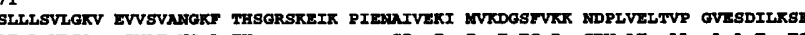

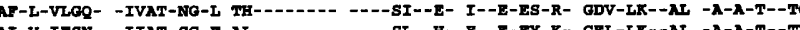

141

ASLLYEKTEQ YRYAILSESI QRNELPEIRI TDFPGGEDNA GGEEPQRVSS LIKXQFMTWQ NRRNPXQLTI T--SOAKT-E T-YKS-LEAV EKDQ--ILDF SKIDLPFATE NDQRRVTL// --B---S--. KORHO-T-N-

NTKIVERDAA LARVSLYEHQ VSQEGRKLID FKYLLNKRAV SQHSVREQEN GYIQPRNEHA VWLAQVSQLE D--RA-RITV ---INR--NI SRV-KSR-D- -SS-LHRQAI AKHA-LEQ-- KYVEAV-ELR -YKSQLE-I M--EA-KLSY ---IKK--GI INTI-QVR-D- -RA-YKEIEI AKHT-IDE-- KYQDAI-ELE -YKASLM-V-

281

KEIRLVRERL ALITNIFRgE IIEKHRKSTD NIVLLEHELT KNRQRKASST -R-PVSGTVQ ELNIHTEOOV SEILSAK--Y QLV-QL-KNE -LD-LRQTT- -TG--TI--A --EE-QQASV -R----VK-- Q-KV--EGMEVLLAK--Q EIV-QL-KAN -LD-LKQAT- -VW--TF--D --NQ-QQVSE -R--.-GT-- Q-KV--ID351

VTTAETLMII VPDNDILEVT ASVLNKDIGF IQPGQEVVIX VDAYPYTRHG YLTGKVKAIT ADSVSVPDTO -1
-1

LVFNIISVD RNDIQGERKK IPVTAGMTVM AEIKTGVRSV ISYLLSPLA TINESLRER

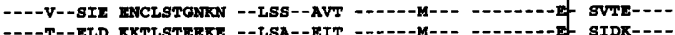

Fig. 3. (a) Sequence comparison of the putative EHEC HlyB protein (top line) with the HlyB protein from $\alpha$-haemolytic plasmid pHly152 (middle line) and LktB (bottom line) from the leukotoxin operon of $A$. actinomycetemcomitans. The Walker 'A' motif (1), the linker peptide (2) and the Walker 'B' motif (3) are boxed and numbered below. Empty circles above the sequences indicate sites of low sequence conservation among HlyB-related proteins, whereas the filled circles represent highly conserved sites. Amino acid substitutions $K^{625} R$ and $G^{654} N$ are
LktD $(60 \%)$, encoded by the Actinobacillus actinomycetemcomitans leukotoxin operon. $\mathrm{HlyB}$ and $\mathrm{LktB}$ are members of a family of ATP-binding transporter proteins found in prokaryotic and eukaryotic cell membranes (Fath \& Kolter, 1993; Koronakis et al., 1993). Members of this family share conserved sequence motifs in their socalled ABC domain (Koronakis et al., 1995). The importance of single amino acid residues and motifs for the transport function has been studied in detail for HlyB of E. coli by Koronakis $e t$ al. (1995). To analyse the putative EHEC HlyB protein we compared its amino acid sequence with E. coli HlyB (Hess et al., 1986) and A. actinomycetemcomitans LktB (Guthmiller et al., 1990a) (Fig. 3a). Highly conserved sites of the HlyB ABC domain comprise the Walker ' $A$ ' (GRSGSGKST) and ' $B$ ' (ILIL) motifs, the linker peptide (LSGGQ), and some single amino acids such as $\mathrm{D}^{630}, \mathrm{H}^{662}$ and $\mathrm{C}^{652}$ (Fath \& Kolter, 1993; Koronakis et al., 1995). These sites are identical in the putative EHEC HlyB protein, suggesting ATPhydrolysing activity. Only two differences from the HlyB $A B C$ domain core sequence were detected in regions of lower sequence conservation: $\mathrm{K}^{625}$ was changed to $\mathrm{R}^{625}$, and $G^{654}$ to $N^{654}$ (see Fig. 3a). The first substitution, $\mathrm{K}^{625} \mathrm{R}$, preceded the Walker B-site, whereas the second one, $\mathrm{G}^{654} \mathrm{~N}$, was not close to any of the highly conserved sites. The same amino acid substitutions were found in the LktB protein (see Fig. 3a).

We performed computer analysis of the putative EHEC HlyD and compared it with HlyD (Hess et al., 1986) and LktD (Guthmiller et al., 1990b)(see Fig. 3b). All three proteins shared a similar pattern of hydrophobicity. A Kyte and Doolittle hydrophobicity plot with a window size of 11 demonstrated that EHEC HlyD possesses a highly hydrophobic segment spanning from amino acid residues 60 to 80 (data not shown). The $\mathrm{C}$-terminal 10 amino acid residues of the putative EHEC HlyD protein share high similarity with the same region of other HlyDrelated proteins (Fig. 3b).

Together with the previously described EHEC $b l y C$ and EHEC bly $A$ genes, the EHEC $b l y B$ and $b l y D$ genes constitute an RTX operon with the gene order $C A B D$. The ORFs for the EHEC bly $C$, bly $A$, bly $B$, and $b l y D$ genes range, respectively, from positions 74 to $580 ; 582$ to 3578 ; 3628 to 5748 ; and 5752 to 7191 . By comparing restriction fragment patterns and hybridizing specific gene probes with restriction enzyme digests of subclones and the entire pO157, the position of the EHEC haemolysin operon was determined to be from $7 \cdot 8 \mathrm{~kb}$ to $15 \mathrm{~kb}$ in the physical map of pO157 (Fig. 2).

marked by arrows. Amino acids identical to the EHEC HlyB sequence are indicated by dashes. (b) Comparison of the amino acid sequence of the putative EHEC HlyD protein (top line) with HlyD (middle line) and LktD (bottom line). The C-terminal 10 amino acids conserved among HlyD-related proteins are boxed. Amino acid residues identical to the EHEC HlyD sequence are indicated by dashes. Obliques have been introduced for optimal alignment of the sequences. 


\section{Replication-associated gene of p0157}

Subclone pE11 (Figs 1a and 2), carrying the $11.4 \mathrm{~kb}$ EcoRI DNA fragment located directly downstream from the EHEC bly genes, was further subcloned. Subclones were subjected to DNA sequencing using M13/pUC18 universal and reverse primers. An overall similarity of approximately $96 \%$ was found with RepFIB, a basic replicon found in large plasmids of the $\mathrm{IncF}$ group (Gannon et al., 1990). By using subclone pB1-5 (Fig. 1a) and customized primers, we detected an ORF of $954 \mathrm{bp}$ highly homologous to orf1 of the RepFIB region (Saul et al., 1989). This ORF has been shown to be essential for replication and highly homologous when investigated from several IncF plasmids. We therefore concluded that the origin of replication of pO157 is partially located on this clone. The entire origin of replication may be encoded by this clone, but this was not determined by this investigation. The EHEC orf1 is located at map position $4.7 \mathrm{~kb}$ to $5.6 \mathrm{~kb}$, close to the EHEC bly operon (Fig. 2).

\section{DISCUSSION}

Although pO157 of E. coli O157:H7 strains has been the subject of several investigations, its role in pathogenicity and virulence has not yet been clearly defined. In contrast to virulence plasmids of other enteropathogenic bacteria like Shigella dysenteriae or Yersinia enterocolitica, no pathogenicity factors have been identified for pO157 since its discovery in 1982. However, we recently discovered a protein encoded by pO157 which possibly has a function in pathogenicity. This protein, EHEC haemolysin, is responsible for the enterohaemolytic phenotype and is a member of the RTX family of exoproteins (Schmidt et al., 1995). Most of the RTX proteins are transported through the cytoplasmic and outer membranes by a unique transport system which is specified by RtxB, RtxD and a genetically unlinked outer-membrane protein (Welch, 1991, 1995). This led us to the hypothesis that the structural basis for the enterohaemolytic phenotype is the result of a defective or inefficient membrane transport system necessary to export EHEC haemolysin.

The phenomenon of retaining an RTX protein on the cell surface was described for the Gram-negative periodontal pathogen Actinobacillus actinomycetemcomitans, which produces leukotoxin (LktA). Although the $l k t B$ and $l k t D$ genes, with high sequence similarity to the $E$. coli bly $B$ and $D$ genes, are present, leukotoxin is not secreted from the cell and remains associated with the outer membrane. Mutational inactivation of the $l k t B D$ genes resulted in a significant decrease of leukotoxin, whereas the transcription of $l k t A$ was unaffected. The $l k t B D$ genes may be responsible for post-transcriptional effects on the leukotoxin relative to protein stability and the leukotoxin location on the cell surface (Guthmiller et al., 1995; Lally et al., 1991).

In this study we demonstrated the presence of EHEC blyB and $b l y D$ genes with high sequence similarity to other RTX transport proteins. From nucleotide sequence analysis data we concluded that no missense mutation disturbs the function of either EHEC HlyB or HlyD. However, the putative EHEC HlyB protein was shown to carry two amino acid substitutions in the $A B C$ domain when compared with the HlyB protein. One of the two, $\mathrm{K}^{625} \mathrm{R}$, is not thought to affect the translocation process. Koronakis et al. (1995) showed that HlyB mutations located at the same position did not influence the transport function. The second amino acid substitution was located in a region with low sequence conservation; no data are available concerning the region's importance. However, the substitution of the small, nonpolar amino acid glycine by the basic asparagine could strongly influence the protein structure and activity. Interestingly, the $\mathrm{LktB}$ protein shows the same amino acid substitutions as EHEC HlyB. Whether these amino acid residues correspond to the specific mode of export of EHEC haemolysin and leukotoxin remains to be elucidated.

A topological model for the translocator HlyD encoded by the $\alpha$-haemolysin operon has been proposed by Schülein et al. (1992). Analysis by PhoA and LacZ fusions and computer-based predictions revealed that the $\mathrm{N}$ terminus (residues 1-60) of HlyD was located in the cytoplasm, followed by a transmembrane domain (residues 60-80). Residues 60-478 are thought to span the periplasmic space. The C-termini of HlyD and HlyDrelated proteins are highly conserved and thought to play an essential role in the translocation process (Schülein $e t$ al., 1992). EHEC HlyD shows the same hydrophobicity pattern and C-terminal sequence conservation as HlyD and $\mathrm{LktD}$, suggesting a function similar to these proteins.

The association of EHEC haemolysin with the bacterial cell may influence the biological activity of this toxin. Pore-forming cytolysins, e.g. E. coli $\alpha$-haemolysin and Staphylococcus aureus $\alpha$-toxin have been shown to damage target cells in a concentration-dependent manner. Bhakdi et al. (1994) showed that high concentrations of $S$. aureus $\alpha$-toxin bind in a non-specific manner to target cells whereas toxin in low concentrations binds specifically to cells expressing a high-affinity binding site. $\alpha$-Haemolysin, which is exported in high concentrations in the environment, is presumed to bind indiscriminately to lipid bilayers. Therefore, the association of EHEC haemolysin with the bacterial cell surface or its extremely low export levels may contribute to the biological function of this toxin in the intimate environment of infecting EHEC O157:H7.

The irregular distribution of restriction sites in pO157 is striking (Fig. 2). By in vitro transcription-translation experiments it was shown that approximately 35 proteins are encoded on this plasmid (Fratamico et al., 1993). A proportion of these proteins seem to be F-plasmidspecific, and therefore necessary for maintenance, replication control, and transfer functions. Hales et al. (1992) reported an approximately $23 \mathrm{~kb} \mathrm{Bam} \mathrm{HI}$ fragment to be present in all investigated plasmids of EHEC strains, which is responsible for the incompatibility and replication functions. We found the fragment corresponded to the $23.5 \mathrm{~kb} \mathrm{Bam} \mathrm{HI}$ fragment spanning the region from $72 \cdot 2 \mathrm{~kb}$ to $2 \cdot 1 \mathrm{~kb}$ in the physical map of pO157 (Fig. 2). 
The occurrence of the replication-associated gene EHEC orf1 located on that fragment supported this finding. Interestingly, the EHEC bly operon is located in the region with numerous restriction sites.

The information available from the physical map and the nucleotide sequence data determined here will enable further systematic investigation of pO157 and the function of EHEC haemolysin. Future studies should identify other possible virulence factors on the plasmid, investigate the regulation of plasmid encoded proteins, and clarify the role of EHEC haemolysin and the entire pO157 in the pathogenesis of $\mathrm{HC}$ and HUS.

\section{ACKNOWLEDGEMENTS}

We thank Jürgen Heesemann, Ivaylo Gentschev and Werner Göbel, Würzburg, Germany, for helpful discussions, and Beatrix Henkel for excellent technical assistance. This work was supported by grant $\mathrm{Ka} 717-2 / 2$ from the Deutsche Forschungsgemeinschaft.

\section{REFERENCES}

Benjamin, M. M. \& Datta, A. R. (1995). Acid tolerance of enterohemorrhagic Escherichia coli. Appl Environ Microbiol 61, 1669-1672.

Bhakdi, S., Grimminger, F., Suttorp, N., Walmrath, D. \& Seeger, W. (1994). Proteinaceous bacterial toxins and pathogenesis of sepsis syndrome and septic shock: the unknown connection. Med Microbiol Immunol 183, 119-144.

Coote, J. G. (1992). Structural and functional relationships among the RTX toxin determinants of Gram-negative bacteria. FEMS Microbiol Rev 88, 137-162.

Dytoc, M., Soni, R., Cockerill, F., De Azavedo, J., Louie, M., Brunton, J. \& Sherman, P. (1993). Multiple determinants of verotoxin-producing Escherichia coli $\mathrm{O} 157: \mathrm{H} 7$ attachment and effacement. Infect Immun 61, 3382-3391.

Fath, M. J. \& Kolter, R. (1993). ABC transporters: bacterial exporters. Microbiol Rev 57, 995-1017.

Fratamico, P. M., Bhaduri, S. \& Buchanan, R. L. (1993). Studies on Escherichia coli serotype O157:H7 strains containing a $60-\mathrm{MDa}$ plasmid and on 60-MDa plasmid-cured derivatives. J Med Microbiol 39, 371-381.

Gannon, V. P., Teerling, C., Masri, S. A. \& Gyles, C. L. (1990). Molecular cloning and nucleotide sequence of another variant of the Escherichia coli Shiga-like toxin II family. J Gen Microbiol 136, $1125-1135$.

Gomez-Duarte, O. G. \& Kaper, J. B. (1995). A plasmid-encoded regulatory region activates chromosomal eae $A$ expression in enteropathogenic Escherichia coli. Infect Immun 63, 1767-1776.

Griffin, P. M. \& Tauxe, R. V. (1991). The epidemiology of infections caused by Escherichia coli O157:H7, other enterohemorrhagic $E$. coli, and the associated hemolytic uremic syndrome. Epidemiol Rev 13, 60-98.

Grinstedt, J., Bennet, P. M. \& Richmond, M. H. (1977). A restriction enzyme map of the R-plasmid RP1. Plasmid 1, 34-37.

Guthmiller, J. M., Kolodrubetz, D., Cagle, M. P. \& Kraig, E. (1990a). Sequence of the lkt $B$ gene from Actinobacillus actinomycetemcomitans. Nucleic Acids Res 18, 5291.

Guthmiller, J. M., Kraig, E., Cagle, M. P. \& Kolodrubetz, D. (1990b). Sequence of the $1 k t D$ gene from Actinobacillus actinomycetemcomitans. Nucleic Acids Res 18, 5292.

Guthmiller, J. M., Kolodrubetz, D. \& Kraig, E. (1995). Mutational analysis of the putative leukotoxin transport genes in Actinobacillus actinomycetemcomitans. Microb Pathog 18, 307-321.

Hales, B. A., Hart, C. A., Batt, R. M. \& Saunders, J. R. (1992). The large plasmids found in enterohemorrhagic and enteropathogenic Escherichia coli constitute a related series of transfer-defective Inc FIIA replicons. Plasmid 28, 183-193.

Heffron, F. (1983). Tn 3 and its relatives. In Mobile Genetic Elements, pp. 223-260. Edited by J. A. Shapiro. New York: Academic Press.

Heffron, F., McCarthy, B. J., Ohtsubo, H. \& Othsubo, E. (1979). DNA sequence analysis of the transposon $\operatorname{Tn} 3$ : three genes and three sites involved in the transposition of Tn3. Cell 18, 1153-1163.

Hess, J., Wels, W., Vogel, M. \& Goebel, W. (1986). Nucleotide sequence of a plasmid-encoded hemolysin determinant and its comparison with a corresponding chromosomal hemolysin sequence. FEMS Microbiol Lett 34, 1-11.

Junkins, A. D. \& Doyle, M. P. (1989). Comparison of adherence properties of Escherichia coli of serotype O157:H7 and a 60 megadalton plasmid-cured derivative. Curr Microbiol 19, 21-27.

Karch, H., Heesemann, J., Laufs, R., O'Brien, A. D., Tacket, C. O. \& Levine, M. M. (1987). A plasmid of enterohemorrhagic Escherichia coli $\mathrm{O} 157: \mathrm{H} 7$ is required for expression of a new fimbrial antigen and for adhesion to epithelial cells. Infect Immun 55, 455-461.

Koronakis, E., Hughes, C., Milisav, I. \& Koronakis, V. (1995). Protein exporter function and in vitro ATPase activity are correlated in ABC-domain mutants of HlyB. Mol Microbiol 16, $87-96$.

Koronakis, V., Hughes, C. \& Koronakis, E. (1993). ATPase activity and ATP/ADP-induced conformational change in the soluble domain of the bacterial protein translocator HlyB. Mol Microbiol 8, 1163-1175.

Lally, E. T., Golub, E. E., Kieba, I. R., Taichman, N. S., Decker, S., Berthold, P., Gibson, C. W., Demuth, D. R. \& Rosenbloom, J. (1991). Structure and function of the $B$ and $D$ genes of the Actinobacillus actinomycetemcomitans leukotoxin complex. Microb Pathog 11, 111-121.

Louie, M., de Azavedo, J. C., Handelsman, M. Y., Clark, C. G., Ally, B., Dytoc, M., Sherman, P. \& Brunton, J. (1993). Expression and characterization of the eae $A$ gene product of Escherichia coli serotype O157: H7. Infect Immun 61, 4085-4092.

O'Brien, A. D., Tesh, V. L., Donohue Rolfe, A., Jackson, M. P., Olsnes, S., Sandvig, K., Lindberg, A. A. \& Keusch, G. T. (1992). Shiga toxin: biochemistry, genetics, mode of action, and role in pathogenesis. Curr Top Microbiol Immunol 180, 65-94.

O'Brien, A. D., Lively, T. A., Chen, M. E., Rothman, S. W. \& Formal, S. B. (1983). Escherichia coli 0157: H7 strains associated with haemorrhagic colitis in the United States produce a Sbigella dysenteriae 1 (SHIGA) like cytotoxin. Lancet 1, 702.

Oelschlaeger, T. A., Barrett, T. J. \& Kopecko, D. J. (1994). Some structures and processes of human epithelial cells involved in uptake of enterohemorrhagic Escherichia coli O157: H7 strains. Infect Immun 62, 5142-5150.

Pridmore, R. D. (1987). New and versatile cloning vectors with kanamycin-resistance marker. Gene 56, 309-312.

Riley, L. W., Remis, R. S., Helgerson, S. D., McGee, H. B., Wells, J. G., Davis, B. R., Hebert, R. J., Olcott, E. S., Johnson, L. M., Hargrett, N. T., Blake, P. A. \& Cohen, M. L. (1983). Hemorrhagic colitis associated with a rare Escherichia coli serotype. $N$ Engl $J$ Med 308, 681-685.

Sambrook, J., Fritsch, E. F. \& Maniatis, T. (1989). Molecular Cloning: a Laboratory Manual, 2nd edn. Cold Spring Harbor, NY: Cold Spring Harbor Laboratory.

Saul, D., Spiers, A. J., McAnulty, J., Gibbs, M. G., Bergquist, P. L. 
\& Hill, D. F. (1989). Nucleotide sequence and replication characteristics of RepFIB, a basic replicon of IncF plasmids. J Bacteriol 171, 2697-2707.

Schmidt, H., Plaschke, B., Franke, S., Rüssmann, H., Schwarzkopf, A., Heesemann, J. \& Karch, H. (1993). Differentiation in virulence patterns of Escherichia coli possessing eae genes. Med Microbiol Immunol 183, 23-31.

Schmidt, H., Karch, H. \& Beutin, L. (1994). The large-sized plasmids of enterohemorrhagic Escherichia coli $\mathrm{O} 157$ strains encode hemolysins which are presumably members of the E. coli $\alpha$-hemolysin family. FEMS Microbiol Lett 117, 189-196.

Schmidt, H., Beutin, L. \& Karch, H. (1995). Molecular analysis of the plasmid-encoded hemolysin of Escherichia coli O157:H7 strain EDL 933. Infect Immun 63, 1055-1061.

Schülein, R., Gentschev, I., Mollenkopf, H. J. \& Goebel, W. (1992). A topological model for the haemolysin translocator protein HlyD. Mol \& Gen Genet 234, 155-163.

Sherman, P., Soni, R., Petric, M. \& Karmali, M. (1987). Surface properties of the Vero cytotoxin-producing Escherichia coli O157: H7. Infect Immun 55, 1824-1829.

Tarr, P. I. (1995). Escherichia coli O157: H7: clinical, diagnostic, and epidemiological aspects of human infection. Clin Infect Dis 20,1-10.

Tesh, V. L. \& O'Brien, A. D. (1991). The pathogenic mechanisms of Shiga toxin and the Shiga-like toxins. Mol Microbiol 5, 1817-1822.

Toth, I., Cohen, M. L., Rumschlag, H. S., Riley, L. W., White, E. H., Carr, J. H., Bond, W. W. \& Wachsmuth, I. K. (1990). Influence of the 60-megadalton plasmid on adherence of Eschericbia coli O157: H7 and genetic derivatives. Infect Immun 58, 1223-1231.

Tzipori, S., Wachsmuth, I. K., Chapman, C., Birden, R., Brittingham, J., Jackson, C. \& Hogg, J. (1986). The pathogenesis of hemorrhagic colitis caused by Escherichia coli $\mathrm{O} 157: \mathrm{H} 7$ in gnotobiotic piglets. J Infect Dis 154, 712-716.
Tzipori, S., Karch, H., Wachsmuth, K. I., Robins Browne, R. M., O'Brien, A. D., Lior, H., Cohen, M. L., Smithers, J. \& Levine, M. M. (1987). Role of a 60-megadalton plasmid and Shiga-like toxins in the pathogenesis of infection caused by enterohemorrhagic Escherichia coli $\mathrm{O} 157: \mathrm{H} 7$ in gnotobiotic piglets. Infect Immun 55, 3117-3125.

Tzipori, S., Gunzer, F., Donnenberg, M. S., deMontigny, L., Kaper, J. B. \& Donohue-Rolfe, A. (1995). The role of the eae $A$ gene in diarrhea and neurological complications in a gnotobiotic piglet model of enterohemorrhagic Escherichia coli infection. Infect Immun 63, 3621-3627.

Wadolkowski, E. A., Burris, J. A. \& O'Brien, A. D. (1990). Mouse model for colonization and disease caused by enterohemorrhagic Escherichia coli O157: H7. Infect Immun 58, 2438-2445.

Wandersman, C. \& Delepelaire, P. (1990). TolC, an Escherichia coli outer membrane protein required for hemolysin secretion. Proc Natl Acad Sci US A 87, 4776-4780.

Welch, R. A. (1991). Pore-forming cytolysins of gram-negative bacteria. Mol Microbiol 5, 521-528.

Welch, R. A (1995). Phylogenetic analyses of the RTX toxin family. In Virulence Mechanisms of Bacterial Pathogens, pp. 195-206. Edited by J. A. Roth and others. Washington, DC: American Society for Microbiology.

Wells, J. G., Davis, B. R., Wachsmuth, I. K., Riley, L. W., Remis, R. S., Sokolow, R. \& Morris, G. K. (1983). Laboratory investigation of hemorrhagic colitis outbreaks associated with a rare Escherichia coli serotype. J Clin Microbiol 18, 512-520.

Yu, J. \& Kaper, J. B. (1992). Cloning and characterization of the eae gene of enterohaemorrhagic Eschericbia coli O157:H7. Mol Microbiol 6, 411-417.

Received 24 August 1995; revised 1 November 1995; accepted 29 November 1995. 